\title{
CODEPENDENCY: A CONCOMITANT FIELD OF INTEREST IN RESEARCH INTO THE PHENOMENON CARING
}

\author{
D van der Wal
}

\begin{abstract}
The growing popularity of caring is evident throughout the nursing profession. Research into the phenomenon caring, however. necessitates that caring as an ethic be distinguished from pseudo caring actions and experiences. Codependence and codependency are proposed as being of a pseudo-caring nature. Research interest into this field of study needs to be kindled.
\end{abstract}

\section{OPSOMMING}

Daar is tekens van 'n groeiende populariteit met betrekking tot omgee (caring) in die verpleeg professie. Navorsing met betrekking tot omgee noodsaak egter dat omgee as ' $n$ etiese beginsel onderskei sal word van pseudo-omgee aksies en ervarings. Mede afhanklikheid (codependence) word voorgestel as pseudo-omgee van aard. Belangstelling in navorsing in hierdie studieveld behoort aangewakker te word.

\section{INTRODUCTION}

The main objective of this article is to kindle an interest in the phenomenon codependency as a concomitant field of research into the phenomenon caring.

The growing focus on caring is evident throughout the nursing profession; in nursing education, nursing management, nursing practice, theorising and research. Not only has the phenomenon of caring been conceprualised in various ways, but it has been classified emphasising its different dimensions. Regarding the latter, Morse et al. (1991) gives a decorous classification which attributes to caring the dimensions of: caring as a human mode of being, caring as a moral imperative and ideal, caring as an affect, caring as an inter-personal relationship, and caring as nursing intervention. Focusing on the concept caring, however, does not illuminate certain subtleties of the phenomenon which could easily be confused with phenomena other than the construct caring. It is necessary therefore, especially in the light of the present wave of concern about. and interest in the phenomenon caring, that caring be distinguished from any possible counterfeit or illusionary phenomenon and experience. Codependence appears to be such a counterfeit phenomenon.

\section{DEFINITIONS OF CARING}

In defining and clarifying the concept caring I would like to range myself with Gaut (1981 19) who states: ... "I do not mean to imply that there will be a single clear and precise meaning [of caring], but rather that the term being defmed has a family of meanings, related and broad in scope." After having studied numerous definitions of the concept caring. Nyberg's summative definition of caring applies. To Nyberg (1989: 15) the preferred definition of caring is: "an interactive commitment in which the one caring is able through a strong self-concept, ordering of life activities, an openness to the needs of others, and the ability to motivate others, to enact caring behaviours that are directed toward the growth of the one cared for, be it an individual or group. Thus, caring is both a philosophy and a milieu created..for the purpose of encouraging caring relationships"... (Nyberg 1989: 15). The latter two concepts, philosophy and milieu are noteworthy. These are related to the main components found in the reconstruction of a caring encounter namely, an emotions/cognitive and an activities component. The emotions/cognitive component and the view of caring as a philosophy are both further directly related to the underlying assumption of caring as an ethic in nursing and thus as a collective diffuse moral and ethical conscience within the nursing profession.

\section{DEFINITIONS OF CODEPENDENCY}

Codependency can be defined on several levels - as a psychological concept, as a working guide for patients (codependents) and as a new and discrete disease (Cermak et al. 1989:132). Codependency is both a condition and a process and is self sustaining and addictive (Chappelle \& Sorrentino 1993:42; Ralph 1993:87).

Snow and Willard (quoted by Caffrey and Caffrey 1994:13) defines codependency as:
".. . any act or behavior that shames and does not support the value, vulnerability, interdependence, level of maturity, and accountability/spirituality of a nurse, colleague, or patient."

Other authors define codependency and codependence as:

- the pattern of painful dependency on compulsive behaviours and on approval from others in an attempt to find safety, self-worth, and identity (WegsheiderCruse and Cruse in Clark and Stoffel 1992:822);

- self-defeating behaviours that diminish an individual's capacity to initiate or participate in loving relationships (Larson in Yates and McDaniel 1994:32);

- a primary disease of lost selfhood (Whitefield in Yates and McDaniel 1994:32);

- any act or behavior of a nurse that meets others' needs at the expense of her own (Yates and McDaniel 1994:33);

- a neglect of one's personal needs because of an extreme preoccupation with external objects and persons ( Cermak et al. 1989:131)

\section{FEATURES AND OUTCOMES OF CODEPENDENCY:}

From the above definitions, certain features and outcomes of codependence can be abstracted but it must be noted that some of the behaviours identified with codependency can exist outside the disease entity (Sherman et al. 1989:27; Farnsworth and Thomas 1993:181 ).

The general features and outcomes of codependency include:

- Caring for others at the expense of caring for oneself (Caffrey and Caffrey 1994:13);

- Enmeshment of one's own personal identity, needs, and feelings in caring for others, (Caffrey and Caffrey 1994:13), distorted boundaries, and not being able to distinguish other's responsibilities and problems from one's own (Yates and McDaniel 1994:34). Codependents thus 
have difficulty perceiving themselves as having an identity outside that of their role as carer;

- Both participants in the relationship are involved in attempts to control one another, places, things and the outcome of events and neither participant is empowered in a way that fosters self-actualization (Caffrey and Caffrey 1994:13; Yates and McDaniel 1994:34);

- Feelings of powerlessness that precede bumout (Caffrey and Caffrey 1994:15);

- Codependency (or caretaking) is motivated by false feelings of duty or of responsibility for others and has a basis of fear rather than love (Caffrey and Caffrey 1994:15);

- Codependent "caring" is fuelled by fear of rejection, abandonment, failure, or conflict which leads to feelings of shame, guilt, anger, or jealousy (Caffrey and Caffrey 1994:15);

- Codependent "caring" is dependent on clients and others in a bureaucracy/ patriarchy to feed one's self-esteem, to make one feel worthwhile, competent and happy (Caffrey and Caffrey 1994:15; Yates and McDaniel 1994:34);

- Dishonesty and self deception by minimising one's problems and emotions;

- Being out of touch with one's feelings;

- Perfectionism;

- Low self-esteem;

- Inability to accept one's innate worth as a person;

- Fear, anxiety;

- Depression;

- Self-centredness;

- Going to extremes with work relationships

- Assuming a martyr role;

- Distorted perception of reality; the super nurse syndrome (Cermak et al. 1989:134-135; Kijek 1989:11; Sherman et al. 1989:26; Zerwekh \& Michaels 1989:112; Bennett et al. 1992:80B; Clark and Stoffel 1992:821-822; Farnsworth and Thomas 1993:181; Ralph 1993:87; Caffrey and Caffrey 1994:15; Yates and McDaniel 1994:34; ).

Different major areas regarding codependence surfaced as different authors categorised these attributes. Summers (1992:70-71) summarises these features and outcomes in five categories, namely: control, guilt, struggling consciousness, damaged boundaries, and denial. Ralph (1993:87-88) identifies the codependent nurse as the professional rescuer caught up in the triangle of codependent roles of rescuer, persecutor, and victim, ultimately resulting in bumout. According to Fagan-Pryor and Haber (1992:26), the core areas of symptoms in codependency are: levels of self-esteem. difficulty in setting and maintaining boundaries, over responsible and overcommitting oneself, and experiencing difficulty in living moderately. Davidhizar and Eshleman (1992:16-17) see the major characteristics of codependency as: dependency on others, over sensitivity, excessive feelings of responsibility, guilt over not meeting the expectations of others, and poor self-esteem. According to Herricks (1992:14), the major areas of concern in codependency entail: low self-esteem, over-control, dependency, perfectionism, super-responsibility, repression of feelings, loss of spirituality, manipulation, the care taker role, and denial. Care taking in fact means taking care away from the client. According to Bennett et al. (1992:80C) caretaking entails constantly trying to anticipate and meet needs of others and doing for others what they can do for themselves. It is thus quite understandable why Clark and Stoffel (1992:823) warn that codependency could lead to workaholism.

\section{CARING IN COMPARISON TO CODEPENDENCY}

Herricks (1992:12) points out that the codependency rhetoric uses words that define "caring." To be codependent is to be a caretaker, to be an enabler, and the like. This naturally necessitates a distinction between the two terms -caring and the counterfeit codependency. However, Mallison (1990:7) and Shelly (1991:3) quote Benner in saying that the codependent label is the latest attempt to pathologize the caring professions - that in fact, it displays society's failure to distinguish between addiction and commitment. It would thus appear that Benner negates the existence of the phenomenon codependence and codependency. In this regard, Summers (1992:70) warns that codependency is a disease so subtle that its symptoms may be perceived as desirable qualities rather than signs of a disabling disorder. On the other extreme, Mullaney (1993:6), in reaction to the "pop-psychology" (Koldjeski 1992:10) usage of the term codependency, and the direct line of comparison that is drawn between caring and codependency, states that: "Codependency has nothing to do with caring. The image of codependency is one of instability, and the process of codependency is about being unrelational". Being "unrelated" or unrelational, is what undermines the essence of caring - the existence of caring, and it is exactly this being unrelated on an intersubjective and interpersonal level, a level of commitment, which is easily either masked or mimicked by codependency attributes.

Montgomery (1993:14) defines caring as "a natural state of social involvement and representativeness that is an integral part of our human condition." Caring, in contrast to codependency, is an empowering relationship, that stems from a solid basis of self-worth, is non-judgemental, spontaneous, and experienced as a spiritual bond between those involved in the caring relationship (Caffrey and Caffrey 1994:15). This empowering relationship is further illustrated in that interdependence is the issue in the caring relationship which is totally different to codependence. When two people become interdependent they share personal power with each other. However, when a person becomes codependent, he gives another person power over his self-esteem (Cermak et al. 1989:132).

This definition of interdependence (as opposed to codependence) provides for the concept accommodation to be considered when distinguishing between caring and codependency. Sherman et al. (1989:27) suggest the following guidelines towards acconmmodation:

- choosing own values based on an understanding or compromise and reality of the situation;

- challenging the right or "shoulds" and resisting other definitions of what reality is;

- differentiating emotions from actions and distinguishing understanding from doing what is expected; and

- recognising that what makes one feel good usually is good.

\section{ORIGIN AND CONTINUANCE OF CODEPENDENCY}

The choice of a career of caring for people in need presumably stems from some needs in the helper, which gain satisfaction when one's working life is spent in an encounter with illness or social disability. The needy person needs to be helped and that help most likely comes from someone who needs to be needed. Unless we recognise the element of personal need leading people into professional caring, we shall fail to see how damaging some forms of over-commitment can be (Campbell 1984:105). Codependence is one form of such over commitment.

Originally, codependency described a person who was emotionally involved with a chemically dependent person and who developed an unhealthy pattern of coping with this situation, as a reaction to another's addiction problem (Summers 1992:70; Zerwekh \& Michaels 1989:109). The core of the etiology of codependence is, however related to low self-esteem. As professionals began to understand codependency better, more groups of people appeared to be codependent. including nurses (Zerwekh \& Michaels 1989:112) and the health care system at large (Clark and Stoffel 1992:823) 
Codependent nurses may be born or made (Yates and McDaniel 1994:33). Fagan-Pryor and Haber (1992:24-28) explain codependency in terms of Bowen's concept of Undifferentiated Self. According to Bowen (Fagan-Pryor and Haber 1992:25), the level of differentiation evidenced in an individual is determined by, what he calls, the togethermess force. The greater the togetherness force, the more an individual's thoughts, feelings, and behaviours are determined by other people, and the greater an undifferentiated sense of self.

Traditionally the cultural script for a "good woman" is the good codependent. Nursing, as primarily a female occupation, provides abundant opportunities for practising codependent caretaking under the guise of caring (Caffrey and Caffrey 1994:13).

Nursing education and socialisation can also help foster codependency. The values of care giving and nurturing that nursing education emphasises make nurses more sensitive to patients' needs, yet they can drive nurses too strongly (Yates and McDaniel 1994:33). As Yates and McDaniel (1994:33) put it, many nurses can remember being praised by their teachers for exhibiting self-sacrifice, for doing even more at the bedside than was expected of them. In giving too much nurses are in jeopardy of losing themselves.

Society, too, expects nurses to be achievers and care takers, strong and capable yet warm and nurturing. Nurses can try too hard to live up to these ideals (Yates and McDaniel 1994:33). Hospitals and other workplaces may likewise encourage or even force codependent behaviour. Hospital administrators and managers may stress putting patients first, irrespective of the cost (Yates and McDaniel 1994:33). In this regard, Klebanoff ( in Caffrey and Caffrey 1994:14) points out that codependency develops to deal with the internalised oppression arising from living in a patriarchal world. According to Roberts (1983:21-30), this intemalised oppression leads to self-hatred and low self-esteem, often expressed in "horizontal violence" towards each other and emulation/imitation of the depersonalised technologically focused practices valued by patriarchy.

It is plausible that the inability to distinguish between caring and codependency exists because social institutions (including health care and educational institutions) depend on codependency and reward it under the guise of commitment. According to Montgomery caring that is free of codependence may actually be considered threatening to health-care systems in which economic well-being is the goal and all decisions are carefully monitored for their contribution to these economic goals. A system that cares for and empowers others loses ultimate control over their decisions. And caring "is beyond control by any authority and therefore is an ultimate expression of freedom and autonomy" (Montgomery 1993:29). In this regard Clark and Stoffel's (1992:827) finding that high scores on codependency are also associated with high scores on external locus of control is significant.

\section{MMPLICATIONS}

It would seem that the major attribute of caring, as proposed by Mayeroff (1971:1), which codependence lacks, is growth - of both the care giver and the receiver of care and caring. Actualisation of the individual's full potential is thus frustrated. The implications for in patient care are obvious if concern is with holistic care. In nursing education, especially in an oppressive, objective Tylerian atmosphere, the counteracting of caring and the promotion of codependence and codependency are a grave possibility. In educational terms, codependency would further the interests of an ill pedagogy, however, will not contribute to the goal of nursing education to produce independent, self-reliant and creative professionals. This is a concern implied by Bevis and Watson (1989) in their exposition of a caring educative curriculum for nursing. It is, however, in research into caring that codependency can be used to some advantage. For instance, during purposive sampling of informants, existing measuring scales of codependency can be used to identify codependent individuals and to exclude them from participation in the research project. In addition to this, especially in nursing education, the need exists to revisit the concept codependence and to investigate its presence among student nurses and the reasons for the existence of this crippling phenomenon amongst them.

\section{MEASURING INSTRUMENTS}

Although several instruments exist, many of these are mere checklists for self-appraisal. The following instruments tested for validity and reliability are mentioned in the literature:

_Codependency Assessment Inventory and Codependency Nursing Self-assessment Inventory (Yates and McDaniel 1994:33); and

_Friel Co-dependency Assessment Inventory (CAI) (Chappelle and Sorrentino 1993:41).

\section{CONCLUSIONS}

Different viewpoints regarding codependency are reflected in the literature. Among these are codependency as an addictive dependence among professionals in helping professions and an accusation of an attempt to pathologize caring.

In view of the present interest in research into the phenomenon caring in all spheres of the nursing profession, the counterfeit of caring, codependency and codependence, need to be considered as a concomitant field of interest for research. Research into the existence of codependency, especially among student nurses, deserves nurse researchers' serious attention.

\section{REFERENCES}

Benneth, S., Robertson, R. \& Moss. P. (1992): Education: learning the pitfalls of codependency. Nursing Management, 23(2):80B-C. 80F, 80H.

Bevis, E. O. \& Watson, J. (1989): Toward a caring curriculum: a new pedagogy for nursing. New York: NLN.

$$
r
$$

Caffrey, R. A. \& Caffrey, P. A. (1994): Nursing: caring or codependent? Nursing Forum, 29(1):12-17.

Campbell, A V (1984): Moderated Love: A Theology of professional Care. Bristol: SPCK.

Cermak, T. L., Hunt, T., Keene, B. \& Thomas, w. (1989): Codependency: more than a catchword Patient Care, 23(15):131-134, 138, 143-144

Chappelle, L. S. \& Sorrentino, E. A. (1993): Assessing codependency issues within a nursing environment. Nursing Management, 24 (5):40-42 and 43.

Clark, J. Stoffel, V. C. (1992): Assessment of codependency behavior in two health student groups. The American Journal of Occupational Therapy, 46(9):821-828.

Davidhizar, R. \& Eshieman, J. (1992): Codependency in the workplace. Hospital Topics, 70(3):15-19.

Fagan-Pryor, E. \& Haber, L. C. (1992): Codependency: another name for Bowen's undifferentiated self. Perspectives in Psychiatric Care, 28(4):24-28.

Farnsworth, B. J. \& Thomas, K. J. (1993): Codependency in nursing: Using a simulation/gaming teaching method. The Joumal of Continuing Education in Nursing, 24(4):180-183.

Gant, D. A. (1981): Conceptual analysis of caring: Research method. In: Caring: An essential human need: edited by M. Leininget. Thorofare: Charles B. Slack. $1981,17-24$.

Herrick, C. A. (1992): Codependency: characteristics, risks, progression, and strategies for healing. Nursing Forum, 27(3):12-19.

Kijek, J. C. (1989): Codependency: what is it? Florida Nurse, 37(2):11.

Koldjeski, D. (1990): Toward a theory of professional nursing canng: A unifying perspective. In: The Caring Imperative in Education; edited by $M$. Leininger and J. Watson, National League for Nursing: New York. 1990. 45-58

Mayeroff, M. (1971): On caring. London: Harper \& Row.

Mallison, M. (1988): Ordered to Care. American Joumal of Nursing, 88(4):25.

Mallison, M. (1990): Swimming in overstatement. American Joumal of Nursing. $90(1): 7$

Montgomery, C. (1993): Healing Through Communication: The Practice of Caring. Newbury Park:SAGE.

Morse, J.M., Bottorf, J.L., Neander, W.L. \& Solberg, S.M. (1991): Comparative analysis of conceptualizations and theories of caring. IMAGE: Joumal of Nursing Scholarship. 23(2):119-126.

Mullaney, M. H. (1993): Codependency: a clear perspective. Joumal of Psychosocial Nursing. 31 (9):6.

Nybers, J. (1989): The eiement of caring in nursing administration. Nursing Administration Quarterly. 13(3):9-16

Ralph, 1. G. (1993): Caught in the clutches of codependency. Revolution: The Joumal of Nurse Empowerment, 3 (3):86-88

Roberts, S. (1983): Oppressed group Behaviours Implications for nursing. Advances in Nursing Science, $S(4): 21-30$.

Dirk an der Wal (MA Cur : UNISA) Senior Lecturer. Department of Advanced Nursing Sciences UNISA 